\title{
Reading Comprehension Monitoring of Expository Discourses in Third to Fifth Grade ADHD Children with/without Vocabulary Delay
}

\author{
Kyungmin Park, Hyojin Yoon \\ Department of Speech-Language Pathology, Chosun University, Gwangju, Korea
}

Correspondence: Hyojin Yoon, $\mathrm{PhD}$ Department of Speech-Language Pathology,

Chosun University, 309 Philmun-daero, Dong-gu, Gwangju 61452, Korea

Tel: $+82-62-230-7462$

Fax: +82-608-5392

E-mail: hyoon@chosun.ac.kr

Received: October 20, 2021

Revised: November 20, 2021

Accepted: November 29, 2021

This paper is based on the master's thesis of the first author.

\begin{abstract}
Objectives: The purpose of this study was to investigate reading comprehension monitoring including three types of error detection (lexical inconsistency, internal inconsistency, external inconsistency) and correction with expository discourse in school-aged children with attention deficit hyperactivity disorder (ADHD). Methods: Nineteen ADHD children with vocabulary delay, $17 \mathrm{ADHD}$ children without vocabulary delay, and 20 typically developing children students from third, fourth, and fifth grades participated in the study. In order to assess comprehension monitoring; expository discourses contained three different types of errors. Comprehension monitoring tasks were presented in the following order: First, children were asked to find out errors in two expository texts of comparison and causation. After finding out errors, children were asked to change the appropriate words verbally. Results: ADHD children with vocabulary delay did show difficultly in reading comprehension monitoring tasks when compared to age-matched typically developing children and ADHD children without language impairment. Internal inconsistency was the most difficult error to identify and correct, and lexical inconsistency was the easiest error for all three groups. Conclusion: The result proposed that even children with ADHD who have no difficulty in basic language and reading skills were likely to have difficulty properly using reading comprehension monitoring, which is closely related to working memory and executive functions. The poor comprehension monitoring skills would negatively influence effective reading comprehension.
\end{abstract}

Keywords: Attention Deficit Hyperactivity Disorder (ADHD), School-aged children, Reading comprehension, Comprehension monitoring, Vocabulary delay
읽기의 궁극적인 목적은 읽기이해로, 글을 읽고 이해하기 위해서 는 말소리지식, 어휘를 포함한 의미지식, 문법 및 구문, 그리고 다양 한 담화유형에 대한 지식이 필수적이다(Kim, 2017). 읽기이해과정 을 구체적으로 살펴보면, 우선 개별적인 어휘나 문장 단위에서 어 휘, 문법 및 구문지식을 활용해서 글을 이해한다. 그 후에 여러 문 장 간의 의미를 파악하고, 독자의 사전지식과 연결해서 전체 담화 의 내용을 통합해야한다.

뿐만 아니라 글을 읽는 동안 끊임없이 사고하고 자신이 글을 이 해하고 있는지 확인하고 조절하는 상위인지능력도 동반되어야 한 다(Gombert \& Gombert, 1992; Pearson, Simoni, Hoff, Kurth, \&
Martin, 2007). 독자는 읽어야하는 텍스트에 주의를 기울이고, 읽 은 단어가 여러 의미가 있다면 여러 의미를 활성화한 후에 관련이 없는 의미는 억제할 수 있어야 한다. 또한 새롭게 들어오는 중요 정 보들을 기억하여 이미 알고 있는 정보와 통합할 수 있는 작업기억 능력이 필수적이다. 마지막으로 필요 정보들을 적절하게 통합하여 이해하고 있는지 점검하는 이해모니터링 능력이 함께 수반되어야 한다(Perfetti \& Adlof, 2012). 이 중 글을 읽으면서 끊임없이 자신의 이해 정도를 점검하는 읽기이해모니터링은 읽기이해의 성공여부를 결정하는 중요한 상위인지능력이다(Berthiaume, Lorch, \& Milich, 2005). 이해모니터링은 텍스트의 의미를 이해하고 있는지 스스로 
확인하는 과정이며, 모니터링의 첫 단계는 이해하지 못한 것을 자 발적으로 인식하는 것이다. 인식한 후에는 이를 해결하기 위해 글 을 다시 읽거나 사전을 찾아보는 등의 전략을 사용한다. 즉, 이해모 니터링은 독자가 텍스트를 읽은 후, 읽은 내용을 이해하였는지 스 스로 지각하고, 이해하지 못하였다면 이해가 가능하도록 의식적으 로 전략을 사용하는 것을 의미한다. 그래서 이해모니터링이 되지 않는다면 적절한 읽기이해는 불가능할 수 있다(Oakhill, Hartt, \& Samols, 2005).

이해모니터링과 관련한 연구들은 읽기장애 아동을 대상으로 읽 기이해와 읽기이해모니터링과의 관련성을 밝히고자 하였다. 읽기 이해부진을 대상으로 이해모니터링 능력을 살펴본 연구들은 읽기 이해부진 아동은 읽기이해모니터링 능력에 어려움을 가진 것으로 나타났으며, 읽기이해모니터링 능력이 읽기이해 능력을 예측하는 유의한 요인으로 설명하였다(Kim, 2014; Oakhill et al., 2005). 또한 최근 언어발달장애 아동을 대상으로 읽기이해모니터링 능력을 살 펴본 Park과 Yoon (2020)의 연구에서는 언어발달장애 아동이 일 반 아동에 비해 이해모니터링 과제에서 저조한 수행력을 보였으며, 이들의 읽기이해모니터링 능력이 읽기이해 능력과 관련이 있음을 보여주었다.

읽기이해모니터링 연구는 일반적으로 연구자가 글에 의도적으 로 적절하지 않은 어휘나 모순되는 내용을 오류로 포함시킨 후에 아동에게 그 부분을 찾고, 적절하게 수정하도록 하는 과제를 사용 하여 이해모니터링 능력을 평가하였다. 이해모니터링 과제에서 빈 번하게 사용되는 오류들은 의미가 없는 단어인 어휘비일관성 오류 (lexical inconsistency error), 앞에 선행된 내용과 불일치하는 내적 비일관성 오류(internal inconsistency error), 일반적인 세상사 지식 에 반하는 외적비일관성 오류(external inconsistency error)이다 (Baker, 1984; Baker \& Anderson, 1982; Kim, 2014). 대표적으로 읽 기이해모니터링을 살펴본 Baker (1984)의 연구에서 사용한 오류를 보면 알버트라는 토끼를 주제로 한 짧은 이야기에서 그 토끼는 갈 색 털을 가지고 있다고 소개한 후에 글의 뒤쪽에서는 다시 하얀 털 을 가지고 있다고 언급하면서 내적비일관성 오류를 포함하였다. 또 한 알버트는 아름다운 'welkin'을 가졌다고 하면서 의미가 없는 단 어인 welkin을 어휘비일관성 오류로 넣었으며, 그 토끼가 가장 좋 아하는 것은 농장에서 자라는 아이스크림이라고 하면서 독자의 세 상사 지식에 반하는 외적비일관성 오류를 포함하였다. 이를 5, 7,9 세의 아동을 대상으로 살펴본 결과 연령이 증가할수록 오류를 잘 찾았으며, 내적비일관성 오류를 찾는 데 가장 어려움을 보였다고 보고하였다. 내적비일관성 오류를 찾기 위해서는 앞서 읽은 내용을 기억하고 새롭게 읽는 내용과 통합하고 조직화해야 하는 과정을 거
쳐야 하는데, 이 과정은 작업기억 능력과 관련이 있다. 만약 작업기 억에서 제한을 보인다면 정보의 저장과 통합이 어렵게 때문에 오류 를 스스로 확인하는 것이 불가능하기 때문이다. 반면, 어휘비일관 성 오류와 외적비일관성 오류는 자신의 어휘집 내에 있는 어휘인 지, 자신이 알고 있는 어휘의 의미와 동일한지 등의 비교적 단순한 처리과정을 필요로 하기 때문에 내적비일관성 오류보다는 쉽게 찾 지만, 이 오류들도 어휘지식과 사전지식, 그리고 추론과 같은 능력 이 수반되어야 찾는 것이 가능하다.

오류 확인과제를 통한 이해모니터링 과제를 살펴보면 독자는 오 류를 확인했을 때 이상함을 인지해야 하고, 이러한 문제를 해결하 기 위해 본인의 언어지식 및 인지 능력을 사용해야 한다. 언어지식 이나 실행기능을 포함한 상위인지 능력에서 취약함을 보인다면 이 해모니터링이 불가능하고, 이는 읽기이해의 어려움을 초래할 수 있 다. 대표적으로 주의력결핍 과잉행동장애(Attention Deficit Hyperactivity Disorder, ADHD) 아동은 이러한 측면에서 취약함을 보이며, 읽기발달에서 잠재적 어려움을 보인다(Bialystok, 2001; Sandra, 2012).

$\mathrm{ADHD}$ 아동은 언어지식이나 단어해독에 어려움이 없음에도 불구하고 낮은 읽기이해 수행력을 보인다고 보고되기도 하였다 (Miller et al., 2013). 대체적으로 짧은 이야기글이나 친숙한 글에서 의 사실적 정보를 이해하는 데에는 크게 어려움이 없지만 인과관 계를 이해해야 하거나 글의 길이가 길어지고 설명담화 등의 친숙하 지 않은 내용이나 개념 등이 포함되는 경우에는 해독이나 언어 능 력에서 어려움을 보이지 않아도 일반 아동에 비해 취약함을 보이 는 것으로 나타났다(Oh, 2005; Purvis \& Tannock, 1997). Brock과 Knapp (1996)은 초등 과학교과 내용을 바탕으로 텍스트 길이에 따 른 읽기이해 능력을 살펴보았으며, 연구결과 $\mathrm{ADHD}$ 아동은 비슷 한 해독 능력을 가진 일반 아동과 비교하여 낮은 읽기이해점수를 받은 것으로 나타났다. 또한 Miller 등(2013)은 해독 능력을 일치시 킨 ADHD 아동과 또래 일반 아동을 대상으로 읽은 후에 다시말하 기 과제를 통해 중요한 정보와 지엽적인 정보의 산출 정도를 비교 하였다. 연구결과 $\mathrm{ADHD}$ 아동은 일반 아동에 비해 중요한 정보를 덜 산출하는 것으로 나타났고, 이러한 결과는 $\mathrm{ADHD}$ 아동의 읽기 이해의 어려움을 보여준다고 설명하였다.

위의 선행연구들을 종합하면 글의 길이가 길어지거나 인과관계 를 이해해야 하거나 친숙하지 않은 개념 등이 포함된 설명글을 읽 고 이해하기 위해서는 다양한 인지 능력이 요구됨에도 불구하고 $\mathrm{ADHD}$ 아동은 인지 능력의 제한을 보이거나 가지고 있는 인지 능 력을 효율적으로 사용하지 못하면서 읽기이해 어려움이 야기된다 고 설명할 수 있을 것이다. 이때 필요한 인지 능력이란 지속적인 주 
의집중(sustained attention), 불필요한 정보에 대한 억제 능력(inhibition), 이미 들어온 정보와 새로 들어오는 정보를 통합하는 작업 기억(working memory) 등과 같은 실행기능이며, 이는 자신의 이해 정도를 끊임없이 점검하는 이해모니터링 능력과 관련이 높다.

실행기능은 $\mathrm{ADHD}$ 아동의 대표적인 결함이며, 읽기이해의 어려 움을 야기하는 대표적인 주요 요인 중 하나이기도 하다(Barkely, 1997). 글을 읽고 이해하기 위해서는 외부에 주의를 돌리지 않고 글 에 지속적으로 주의집중해야 하며(sustained attention), 억제 능력 (inhibition)을 통해 필요한 정보만 활성화하고, 필요하지 않은 정보 는 억제할 수 있어야 하며, 글을 읽으며 이미 들어온 정보와 새롭게 들어오는 정보를 통합하는 작업기억(working memory) 능력이 필 요하다. 하지만 이러한 측면에서 결함을 가진 $\mathrm{ADHD}$ 아동은 글을 조직적이며 결속력 있게 이해하기 위해 자신의 행동을 통제하고 글 을 적절하게 이해하였는지 스스로 점검하는 것을 어렵게 한다. 이 중 작업기억은 과제를 수행하는 동안 이전의 정보를 기억하면서 동 시에 처리할 수 있는 능력으로 읽는 동안 정보를 통합하기 위해 반 드시 필요한 읽기이해의 기반이 되는 능력이다(Pennington \& Ozonoff, 1996). 특히, 앞서 언급한 이해모니터링 연구에서 내적비일관 성 오류는 다른 오류유형과 달리 작업기억과 같은 상위인지 능력 을 필요로 하기 때문에 가장 어려운 오류유형으로 간주하였다. 그 렇다면 작업기억에서의 결함을 보이는 $\mathrm{ADHD}$ 아동은 이러한 종 류의 오류를 확인하는 데 더 어려움을 보이게 되며, 이는 읽은 글을 결속력 있게 이해하는 데 영향을 미치게 된다. 또한 Stern과 Shalev (2013)는 ADHD 청소년은 지속적인 주의집중(sustained attention) 이 또래 일반 아동에 비해 낮고, 이들의 제한된 집중 능력은 낮은 읽 기이해 능력과 관련이 있음을 보고하였다.

$\mathrm{ADHD}$ 아동의 읽기이해모니터링 능력을 구체적으로 살펴본 연 구는 제한적이다. 예외적으로 읽기이해에 어려움이 없는 초등 1-2 학년 $\mathrm{ADHD}$ 아동을 대상으로 이해모니터링을 살펴본 Nam, Hwang 과 $\operatorname{Lim}$ (2012) 연구에서는 외적비일관성 오류를 사용하여 이야기 담화에서 읽기이해모니터링 능력을 살펴보았다. 연구결과 일반 아 동에 비해 저조한 수행력을 보이는 것으로 나타나 $\mathrm{ADHD}$ 아동이 읽기이해모니터링에 어려움을 보인다는 것을 확인할 수 있었다. 또 한 Berthiaume, Lorch와 Milich (2010)는 7-12세의 ADHD 남아를 대상으로 추론 능력과 읽기이해모니터링 능력을 살펴본 결과, 추론 능력과 이해모니터링 능력 모두 또래 아동에 비해 어려움을 보이는 것으로 나타났다. 연구자들은 추론 능력과 이해모니터링의 결함이 글을 이해하는 것을 방해하고, 결국 학습의 실패로 연결된다고 설 명하였다.

읽기는 학습에 중요한 도구로 읽기의 어려움이 학습에 큰 영향
을 미칠 수 있다. 그렇기 때문에 $\mathrm{ADHD}$ 아동이 읽기이해에서 보이는 어려움에 대한 요인을 면밀히 살펴보는 것은 중요하다. 특히, $\mathrm{ADHD}$ 아동이 결함을 보이는 실행기능과 밀접하게 관련되어 있는 이해모 니터링 능력은 이들의 읽기이해 특성과 부진을 설명할 수 있는 요인 일 수 있기 때문에 ADHD 아동의 읽기이해모니터링을 살펴보는 연구가 필요할 것이다. $\mathrm{ADHD}$ 아동의 읽기이해모니터링을 살펴보 았던 선행연구들이 하나의 오류에 초점을 두거나 언어 능력은 고려 하지 않은 제한점이 있었다. 따라서 본 연구에서는 이러한 요인을 고 려하여 $\mathrm{ADHD}$ 아동의 읽기이해모니터링 능력을 살펴보고자 한다.

본 연구에서는 해독이 안정화되고 학습을 위한 읽기이해가 발달 하는 시기인 초등 3-5학년의 $\mathrm{ADHD}$ 아동과 또래 일반 아동을 대 상으로 읽기이해모니터링 능력을 살펴보고자 한다. 특히, 읽기이해 에는 어휘를 포함한 언어지식이 중요한 요인이기 때문에 $\mathrm{ADHD}$ 아 동을 어휘발달지연을 동반한 $\mathrm{ADHD}$ 아동과 어휘발달에 어려움이 없는 단순 $\mathrm{ADHD}$ 아동으로 나누어 읽기이해모니터링 능력을 구체 적으로 살펴보고자 하였다. 앞서 선행연구에서 언급한 것처럼 친숙 하지 않은 주제가 포함된 설명담화처럼 인지적 요구가 높은 읽기이 해에서 $\mathrm{ADHD}$ 아동이 읽기이해에서 어려움을 보였다는 연구결과 에 근거하여 본 연구에서는 초등 3-5학년 수준의 설명담화를 사용 하여 읽기이해모니터링 능력을 살펴보고자 하였다. 이전 선행연구 와 달리 본 연구에서는 읽기이해모니터링 연구에서 빈번하게 사용 되는 어휘, 내적, 외적비일관성 오류를 모두 포함하여 오류확인 및 수정과제를 실시하였다. 이를 통해 어휘발달지연을 동반한 $\mathrm{ADHD}$ 아동, 일반적인 어휘발달을 하는 단순 $\mathrm{ADHD}$ 아동, 그리고 일반 아동 간에 설명담화 읽기이해모니터링 능력에서 차이가 있는지를 살펴보고 오류유형 간에 유의한 차이가 있는지를 탐색해 보고자 하였다.

\section{연구방법}

\section{연구대상}

본 연구는 초등 3-5학년의 ADHD 아동과 학년을 일치시킨 아동 의 읽기이해모니터링 특성을 살펴보았다. 본 연구에서는 $\mathrm{ADHD}$ 아동을 어휘발달지연을 보이는 아동과 어휘발달에 어려움이 없는 두 집단으로 나누어 살펴보았다. 어휘 능력을 근거로 하여 두 집단 으로 나눈 이유는 $\mathrm{ADHD}$ 아동이 언어장애를 동반하는 비율이 높 고(Tannock \& Schachar, 1996), 언어장애는 읽기발달에 영향을 미 칠 수 있기 때문에 언어 능력에 따른 집단을 선정하고자 하였다. 특 히, 언어 능력 중 어휘 능력이 읽기발달과 관련이 높은 요인이기 때 문에 본 연구에서는 어휘 능력으로 $\mathrm{ADHD}$ 아동 집단을 나누어 살 
펴보고자 하였다(Ouellette, 2006; Ricketts, Nation, \& Bishop, 2007). 본 연구에는 어휘발달지연을 동반한 $\mathrm{ADHD}$ 아동 19 명, 어휘발달 에 어려움이 없는 $\mathrm{ADHD}$ 아동 17 명(이하 단순 $\mathrm{ADHD}$ ), 그리고 초 등 3-5학년의 일반 아동 20 명이 참여하였다.

먼저, $\mathrm{ADHD}$ 집단 선정기준은 다음과 같다. (1) 소아정신과 전문 의에 의해 2-3년 이내 $\mathrm{ADHD}$ 진단을 받았거나, 아동.청소년 행동 평가척도(K-CBCL-18; Oh, Kim, Ha, Lee, \& Hong, 2010)검사에서 T점수 65점 이상으로 $\mathrm{ADHD}$ 진단받은 아동으로, (2) 한국 비언어 성 지능검사(K-CTONI-2; Park, 2014)에서 비언어성 지능이 80점 이상인 아동이며, (3) 읽기이해모니터링 과제를 수행하는 데 해독 의 어려움이 없는 아동으로 선정하고자 한국어 읽기 검사 $(\mathrm{KOL}-$ $\mathrm{RA}$; Pae, Kim, Yoon \& Jang, 2015)의 해독 검사에서 백분위 10 초 과인 아동으로 선정하였다. (4) 다른 신경학적 문제가 없으며, 검사 당일 약물을 복용하지 않는 것에 동의하는 아동으로 선정하였다. 마지막으로 (5) 수용·표현어휘력검사(REVT; Kim et al., 2009)의 수용어휘 검사에서 -1.25 표준편차 이하이면 어휘발달지연을 동반 한 $\mathrm{ADHD}$ 아동으로, -1 표준편차 이상이면 단순 $\mathrm{ADHD}$ 아동으로 선정하였다. 일반 아동은 (1) 비교적 짧은 시간에 부모보고를 통해 $\mathrm{ADHD}$ 유무를 확인할 수 있는 코너스 단축형 부모 평정척도(KARS; Kim et al., 2003)에서 16점 이하이며, (2) K-CTONI-2 결과 80 점 이상, (3) REVT의 수용어휘 검사 결과 -1 표준편차 초과, (4) KOLRA의 해독 검사 결과 백분위 10 초과이고, (5) 그 외 부모나 교 사에 의해 감각 및 운동문제를 동반하지 않은 아동으로 품행장애, 불안이나 우울 등 공존질환이 없다고 보고된 아동으로 선정하였다.

구체적인 대상자 정보는 Table 1에 제시하였다. 각 집단 간에 비언

Table 1. Participant's characteristics

\begin{tabular}{|c|c|c|c|c|}
\hline & $\begin{array}{l}\text { ADHD with VD } \\
\quad(\mathrm{N}=19)\end{array}$ & $\begin{array}{l}\text { Only ADHD } \\
(\mathrm{N}=17)\end{array}$ & $\mathrm{TD}(\mathrm{N}=20)$ & $F$ \\
\hline Age (month) & $118.74(9.62)$ & $119.06(10.31)$ & $120.65(11.05)$ & .19 \\
\hline $\mathrm{K}-\mathrm{CBCL} \mathrm{L}^{\mathrm{a}}$ & 84.86 (8.21) & $85.0(7.72)$ & & $1,031.5$ \\
\hline K-ARS ${ }^{b}$ & & & $4.95(2.85)$ & 54.10 \\
\hline K-CTONI-2 ${ }^{c}$ & $106.50(4.03)$ & $106.35(2.99)$ & $109.15(5.19)$ & 2.58 \\
\hline $\mathrm{REVT}^{\mathrm{d}}$ & 80.56 (16.30) & $104.47(10.94)$ & $109.55(14.11)$ & $21.08^{* * *}$ \\
\hline $\begin{array}{l}\text { Decoding of } \\
\text { KOLRA }^{\mathrm{e}}\end{array}$ & $68.81(4.80)$ & $70.88(4.75)$ & $70.45(6.90)$ & .60 \\
\hline
\end{tabular}

Values are presented as mean $( \pm \mathrm{SD}) ;{ }^{* * *} p<.001$.

${ }^{\mathrm{a}} \mathrm{K}-\mathrm{CBCL}=\mathrm{T}$ Score of the Korea Child Behavior Check List for ages 6-18 (Oh, Kim, $\mathrm{Ha}$, Lee, \& Hong, 2010), ' $\mathrm{K}-\mathrm{ARS}=$ Korean ADHD Rating Scales (K-ARS) (Kim et al., 2003), ' $K-C T O N I-2=$ Standard score of the Korean version of Comprehensive Test of Nonverbal Intelligence 2nd edition (Park, 2014), 'REVT = Raw scores of the Recep-

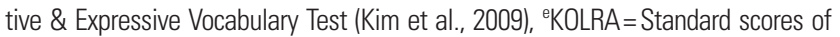
the Korean Language-based Reading Assessment (Bae et al., 2014).

$A D H D$ with $V D=A D H D$ children with Vocabulary delay; Only $A D H D=A D H D$ children without vocabulary delay; TD= Typically developing children.
어성 지능과 해독 능력은 차이가 없는 것으로 나타났으며, 수용어 휘 능력은 단순 $\mathrm{ADHD}$ 아동과 일반 아동 간에는 차이가 없었고, 어휘발달지연을 동반한 $\mathrm{ADHD}$ 아동은 두 집단 모두와 통계적으 로 유의한차이가 있는 것으로 나타났다.

\section{연구과제}

본 연구에서는 연구자가 제작한 설명담화 글 과제를 사용하여 이해모니터링을 평가하였다. 설명담화는 초등 3 학년부터 본격적으 로 나오기 시작하는 비교대조와 인과유형으로 선정하였으며, 설명 글은 다문화가정 초등학생의 언어 및 읽기교육을 위한 교재인 "함 께 읽고 말해요” 4단계 수준(Pae, Jung, Kim, \& Jin, 2010)에 포함된 글을 선택하였다. “함께 읽고 말해요”는 동일한 주제의 글을 어휘 와 구문적 난이도에 따라 1단계부터 4 단계로 나눈 책으로 4 단계가 가장 어려운 어휘와 복잡한 구문으로 구성되었다. 본 연구의 대상 자가 초등 중-고학년이기 때문에 4단계를 선택하였으나 3학년 아 동이나 어휘발달지연 아동을 고려하여 어휘의 난이도와 구문길이 및 복잡성을 수정 및 보완하였다. 또한 두 담화의 어휘와 구문적 특 성을 비슷한 수준으로 조절하여 이해모니터링 과제를 제작하였다. 비교대조의 주제는 명절이며(제목: 추석과 설날), 인과유형의 주제 는 온난화(제목: 빙하가 녹고 있다)이다. 두 담화는 각각 13 개의 문 장으로 구성되었으며, 단문 9 개와 복문 4 개로 구성하였다. 또한 각 담화의 전체 어절 수는 131 개이다. 의미적 난이도를 고려하기 위해 $\operatorname{Kim}$ (2003)의 ‘등급별 국어교육용 어휘’에서 1-3등급에 포함된 어 휘가 이야기의 $90 \%$ 이상차지하도록 구성하였다.

이해모니터링은 적절하지 않은 어휘나 모순되는 내용을 찾고, 적 절하게 수정하는 방법을 사용하여 측정하였다. 본 연구에서는 이 해모니터링 연구에서 빈번하게 사용하는 어휘비일관성 오류(lexical inconsistency errors), 외적비일관성 오류(external inconsistency errors), 그리고 내적비일관성 오류(internal inconsistency errors) 세 가지 유형을 포함하였다(Baker1984; Garner \& Reis, 1981).

첫번째 오류인 어휘비일관성 오류는 의미가 없는 비단어로 2음 절 무의미 단어가 오류로 포함되었다(ex. 쪼탕, 벙피). 두 번째 오류 인 내적비일관성 오류는 문맥 내 내용이 불일치한 오류로, 글의 앞 부분에서 제시한 문장의 내용과 일치하지 않는 내용이 글의 뒷부 분에 제시되는 오류이다. 예를 들면 '추석과 설날'의 글에서 글의 앞 부분에 ‘우리나라의 큰 명절은 설날과 추석’이라고 언급한 후 글의 뒷부분에서 '가장 큰 명절인 단오는 집안의 어른들께 인사를 드리 고 좋은 이야기를 듣는다' 라고 제시함으로써 앞, 뒤 문장의 내용이 불일치하도록 하였다. 마지막 오류는 외적비일관성 오류이며, 아동 이 가지고 있는 배경지식에 반하는 내용이 포함된 오류이다. 예를 
들어 “비가 많이 내려 홍수가 발생하게 된다”의 '홍수를 “비가 많 이 내려 가뭄이 발생하게 된다.”의 '가뭄'으로 바꾸었는데, 아동은 자신이 가진 배경지식과 텍스트의 내용이 일치하지 않는다는 것을 인지하고 찾을 수 있어야 한다. 연구에서 사용된 설명담화와 오류 의 예시는 Appendix 1에 제시하였다. 본 연구에서는 두 개의 담화 에 세 가지 오류유형을 각 1 번씩 넣어 각 담화에 포함된 총 오류 수 는 3 개이며, 전체 오류 수는 6 개이다.

초등 3-5학년 아동이 글에 포함된 오류를 적절하게 찾고 수정할 수 있는지를 확인하기 위해 초등 3-5학년 일반 아동 3명을 선정하여 예비연구를 실시하였다. 예비검사를 실시하여 2명 이상의 아동이 찾지 못하거나적절한 의미로 고치지 못하는 오류는 수정하였다.

두 설명담화에 대한 내용타당도 검증은 언어병리학 박사학위를 소지한 언어치료사 2 인, 국어국문학 박사학위를 소지한 1 인과 읽기 이해모니터링 관련 연구와 언어병리학 석사학위를 소지한 언어치 료사 1 인에게 타당도를 검증하였다. 글에 제시된 어휘, 구문, 주제 와 내용 및 3 가지 오류유형(어휘, 내적, 외적비일관성)의 적절성에 대한 내용타당도를 확인하기 위해 Likert 5점척도(5점 '매우 타당 하다', 4점 ‘타당하다', 3점 ‘보통이다', 2점 '타당하지 않다', 1점 '매 우 타당하지 않다)로 실시하였다. 적절한 주제와 내용과 관련한 타 당도 검사 결과는 평균 4.4 점, 오류유형과 관련한 타당도 검사 결과 는 평균 4.5 점이었다.

\section{연구절차}

모든 검사자는 연구자가 직접 진행하였으며, 연구가 원활하게 진 행될 수 있도록 조용하고 독립된 공간에서 진행하였다. 대상자 선정 을 위한 선별검사를 먼저 실시한 후에 본 연구과제를 실시하였다.

본 연구과제인 이해모니터링 과제는 오류 확인과제를 먼저 실시 한 후에 오류 수정과제를 실시하였다. 오류 확인과제에서는 아동에 게 오류가 포함된 글을 읽은 후에 의미가 이상하거나 모순되는 내 용이 있으면 줄을 긋도록 요구하였다. 검사자는 아동에게 "선생님 이 이제부터 2 개의 이야기를 보여줄 거예요. 00 이가 읽다가 이상한 부분이 있으면 밑줄 그어주세요.” 라고 지시하였다. 만약 글을 읽는 동안 아동이 이상한 부분에 대해 질문하면 " 00 이가 먼저 표시해 놓고 나중에 질문해주세요." 라고 하였다. 오류 확인과제를 마친 후 에 오류 수정과제를 실시하였다. 오류 수정과제는 아동이 오류 확 인과제에서 찾은 부분을 글의 내용에 맞게 적절하게 수정하여 말 하도록 요구하였다. 검사자는 " 00 이가 읽으면서 이상한 부분에 밑 줄을 잘 그어주었어요. 이제 00 이가 밑줄 그은 부분에 대해서만 적 절한 말로 고쳐서 말해주세요.” 라고 말한 뒤 아동의 수행을 기다 렸다. 연구자는 대상자에게 2 개의 설명담화의 순서효과를 배제하
기 위하여 역균형화하여 제시한 후 오류 확인, 오류 수정 순으로 연 구를 진행하였다.

\section{채점기준}

각 담화 내에 3 개의 오류유형이 1 개씩 포함되어, 총 2 개의 담화에 는 6개의 오류가 포함되어 있다. 아동이 오류를 찾은 경우 1 점, 오류 를 적절하게 수정한 경우에 한하여 1점을 추가로 제공하여 이해모 니터링 총점은 12 점이었다.

\section{자료의 통계처리}

본 연구에서 수집된 자료를 SPSS version 21.0을 사용하여 다음 과 같이 분석하였다. 먼저, 설명담화에서 세 집단 간 읽기이해모니 터링 점수의 차이가 있는지 알아보기 위하여 일원분산분석(oneway ANOVA)를 실시하였다. 두 번째, 세 집단 별 세 개의 오류유형 에 따라 이해모니터링 점수에 차이가 있는지 여부를 살펴보기 위 해 이요인 혼합분산분석(Two-way mixed ANOVA)를 실시하였으 며, 사후분석은 Bonferroni 분석을 실시하였다.

\section{연구결과}

\section{세 집단 간 설명담화 읽기이해모니터링 능력}

각 집단의 읽기이해모니터링 총점의 기술통계 결과는 Table 2에 제시하였다. 집단 간 평균을 비교한 결과 어휘발달지연을 동반한 $\mathrm{ADHD}$ 아동이 가장 수행력이 낮았고, 단순 $\mathrm{ADHD}$ 아동, 일반 아 동 순으로 나타났다.

세 집단 간 읽기이해모니터링 총점에서 차이가 있는지를 살펴보 기 위해 일원분산분석(one-way ANOVA)를 실시한 결과 집단 간 에 유의한 차이가 있는 것으로 나타났다 $(F=22.83, p<.001)$. 구체 적으로 어느 집단 간 차이를 보이는지 살펴보기 위해 Bonferroni 사후검정을 실시한 결과, 단순 $\mathrm{ADHD}$ 아동과 어휘발달지연을 동 반한 $\mathrm{ADHD}$ 아동 $(p<.05)$, 일반 아동과 어휘발달지연을 동반한 $\mathrm{ADHD}$ 아동 $(p<.001)$ 과 일반 아동과 단순 $\mathrm{ADHD}$ 아동 $(p<.01)$

Table 2. Mean and standard deviation of total scores of comprehension monitoring and each score of error types

\begin{tabular}{lcccc}
\hline Group & Lexical error & Internal error & External error & Total \\
\hline ADHD with VD & $1.79(1.58)$ & $.21(.53)$ & $.32(.67)$ & $2.32(2.78)$ \\
Only ADHD & $2.59(1.17)$ & $.76(1.34)$ & $2.06(1.51)$ & $5.41(4.02)$ \\
TD & $3.35(1.08)$ & $1.75(1.58)$ & $2.75(1.29)$ & $7.85(3.95)$ \\
\hline
\end{tabular}

$A D H D$ with $V D=A D H D$ children with Vocabulary delay; Only $A D H D=A D H D$ children without vocabulary delay; TD= Typically developing children. 
간에 차이를 보이면서 세 집단 모두 유의한 차이가 있는 것으로 나 타났다.

\section{각 집단과 오류 유형에 따른 설명담화 읽기이해모니터링 능력}

집단과 오류유형에 따른 설명담화 읽기이해모니터링 점수는 $\mathrm{Ta}-$ ble 2에 제시하였다. 집단과 오류유형에 따른 이해모니터링 점수에 차이가 있는지를 확인하기 위해 이요인 혼합분산분석을 실시한 결 과 집단 $(F=22.60, p<.001)$ 과 오류유형 $(F=31.21, p<.001)$ 간에 주 효과가 나타났다. 하지만 오류유형과 집단에 따른 읽기이해모니터 링 점수의 상호작용효과는 유의하지 않은 것으로 나타났다 $(F=1.68$, $p=.159)$.

아동들은 어휘비일관성 오류를 가장 잘 찾고 수정하였으며, 내 적비일관성 오류를 찾고 수정하는 데 가장 어려움을 보이는 것으 로 나타났다. 오류유형 간 차이를 확인하고자 Bonferroni 사후검 정 검사를 실시한 결과, 어휘비일관성과 내적비일관성 $(p<.001)$, 어 휘비일관성과 외적비일관성 $(p<.001)$ 과 내적비일관성과 외적비일 관성 $(p=.003)$ 간 차이를 보이면서 모든 오류유형 간에 유의한 차 이가 있는 것으로 나타났다. 각 집단 내에서 오류유형 간 차이를 살 펴본 결과, 어휘발달지연을 동반한 $\mathrm{ADHD}$ 아동은 어휘와 내적 $(p=.001)$, 어휘와 외적 $(p=.001)$ 비일관성 오류 간에는 차이가 있으 나 내적과 외적비일관성 오류에서는 차이가 없는 것으로 나타났다. 반면, 단순 $\mathrm{ADHD}$ 아동과 일반아동은 어휘와 내적 $(p<.001, p=.001$, respectively), 내적과 외적 $(p=.009, p=.016$, respectively) 비일관성 오류간에는 차이가 있었으나 어휘와 외적비일관성 오류 간에는 유 의한 차이가 없는 것으로 나타났다.

\section{논의 및 결론}

본 연구는 초등학교 3-5학년 어휘발달지연을 동반한 $\mathrm{ADHD}$ 아 동과 단순 $\mathrm{ADHD}$ 아동, 그리고 학년을 일치시킨 일반 아동을 대상 으로 설명담화의 읽기이해모니터링 능력을 살펴보았다. 읽기이해 모니터링을 살펴보기 위해 이해모니터링 연구에서 빈번하게 사용 하는 세 개의 오류유형을 설명담화글에 의도적으로 넣고, 아동에 게 글의 내용에 적절하지 않은 오류를 찾고 수정하도록 하는 과제 를 사용하여 연구를 진행하였다.

우선 세 집단 간에 설명담화 읽기이해모니터링 능력에 차이가 있 는지를 살펴본 결과 세 집단 간 모두 통계적으로 유의한 차이를 보 이는 것으로 나타났다. 어휘발달지연을 동반한 $\mathrm{ADHD}$ 아동이 읽 기이해모니터링 과제에서 가장 어려움을 보였으며, 단순 $\mathrm{ADHD}$ 아 동, 일반 아동 순으로 수행력이 좋은 것으로 나타났다. 본 연구의 이
해모니터링 과제에서 모든 오류유형을 찾고 수정했을 때 만점은 12 점인데, 일반아동은 평균 7.85 , 단순 $\mathrm{ADHD}$ 아동은 5.41 , 그리고 어 휘발달지연을 동반한 $\mathrm{ADHD}$ 아동은 2.32점으로 나타났다. 이는 $\mathrm{ADHD}$ 아동은 언어발달지연의 여부와 관계없이 읽고 이해하는 과정에서 자신의 이해 정도를 확인하는 데 어려움이 있다는 것을 보여준다. 본 연구결과는 $\mathrm{ADHD}$ 아동의 이해모니터링을 살펴보았 던 선행연구들과도 일치하는 결과이다(Berthiaume et al., 2010; Miller et al., 2013; Nam et al., 2012). Nam 등(2012)의 연구에서도 읽기이해에 어려움이 없는 초등 1-2학년 $\mathrm{ADHD}$ 아동도 또래 일반 아동에 비해 읽기이해모니터링에서 어려움을 보이는 것으로 나타 났다. 본 연구결과와 함께 종합하여 본다면, 어휘 능력이나 읽기이 해 능력에 관계없이 $\mathrm{ADHD}$ 아동은 이해모니터링에서 어려움을 보 이는 것으로 해석할 수 있을 것이다.

$\mathrm{ADHD}$ 아동이 자신의 이해 정도를 의식적으로 점검하는 데 어 려움을 보이는 것은 이들의 주의력 결함, 억제 및 작업기억 등과 같 은 실행기능과 관련하여 설명할 수 있다. 대표적으로 이해모니터링 의 수행력에 영향을 미친 요인은 작업기억으로 설명할 수 있다. 이 미 선행연구들을 통해 $\mathrm{ADHD}$ 아동은 작업기억에서의 결함을 가 지고 있으며(Miller et al., 2013; Park \& Shin, 2010), 작업기억 능력 이 이들의 읽기이해 능력을 설명해 주는 예측력 있는 요인으로 나 타나기도 했다(Miller et al., 2013). Miller 등(2013)의 연구에서는 읽은 내용을 다시 말하도록 요구했을 때 얼마나 중요한 내용을 말 하는지를 살펴본 결과, $\mathrm{ADHD}$ 아동은 일반 아동보다 적게 산출했 으며, 작업기억 능력이 읽기이해와 읽은 후 중요한 내용을 말하는 것을 설명해 주는 요인으로 나타났다. 읽기이해는 이전 정보와 새 롭게 들어오는 정보의 통합을 통해 심적 표상(mental representation)을 계속적으로 재구성해 나가는 지속적인 과정이며, 작업기억 이 이를 가능케 해준다. 특히, 본 연구에서 사용한 오류들 중 내적 비일관성 오류는 텍스트 내에 서로 모순되는 내용을 포함하는 것 으로, 글의 전반적인 내용을 계속적으로 저장하고 조직화해야만 오류를 찾는 것이 가능하기 때문에 $\mathrm{ADHD}$ 아동에게는 어려울 수 밖에 없다. $\mathrm{ADHD}$ 아동의 제한된 작업기억 능력은 텍스트의 내용 을 지속적으로 저장하고 통합하는 읽기이해 과정을 어렵게 하는 요인이 된다(Choi \& Jung, 2001; Noh \& Shin, 2007).

뿐만 아니라 $\mathrm{ADHD}$ 아동의 주의력이나 억제 능력도 이해모니터 링 과정에서 어려움을 야기한다. $\mathrm{ADHD}$ 아동은 필요한 정보에만 선택적으로 주의집중 유지하지 못하고, 불필요한 정보나 중요하지 않은 정보를 억제하지 못하는 충동성이 텍스트 내에서 의미적으로 적절하지 않거나 전반적인 내용과 불일치하는 정보를 찾는 것을 방 해하였다(Berthiaume et al., 2010; Walczyk \& Hall, 1989). Berthi- 
aume 등(2010)의 연구에서는 7-12세 ADHD 남아를 대상으로 읽 기이해모니터링을 살펴보았을 때 일반 아동에 비해 낮은 수행력을 보였다고 보고하였다. 읽기이해모니터링의 실패는 자신의 이해를 수정할 기회를 잃어버리는 것이며, 부정확하고 불완전한 내용의 이 해로 이어지게 된다. 결국 $\mathrm{ADHD}$ 아동의 학업성취와도 연결될 수 있다. 흥미롭게도 오류 확인과 수정과제를 분리하여 살펴본 이해모 니터링 연구에서는 $\mathrm{ADHD}$ 아동이나 언어장애 아동 모두 오류를 찾는 데 어려움을 보이나 일단 찾은 오류에 한해서는 의미적으로 적절하게 수정을 할 수 있는 것으로 나타났다(Nam et al., 2012; Park \& Yoon, 2020). 본 연구에서는 오류 확인과 수정과제를 분리하여 분석하지는 않았지만 $\mathrm{ADHD}$ 아동도 오류를 찾은 후에는 의미적 으로 적절하게 수정하는 것으로 나타났다. 이러한 결과는 $\mathrm{ADHD}$ 아동이 다시 읽거나 스스로 질문을 하면서 읽는 과정을 통해 자발 적으로 이해점검을 하는 중재를 받는다면, 좀 더 정확한 글이해가 가능할수 있음을 보여준다.

실행기능을 포함한 상위인지 능력뿐 아니라 언어 능력, 특히, 어 휘지식은 글의 의미를 정확하게 이해하는 데 필수적인 요인 중 하 나이다. Oakhill 등(2005)의 연구보고에 따르면 언어영역에서 어려 움을 보이는 읽기이해부진 아동은 읽기이해 능력이 정상인 아동보 다 낮은 이해모니터링 능력을 보인다는 결과를 보고하며 이해모니 터링 시 언어지식이 필수적이라는 사실을 뒷받침해주고 있다. 본 연구에서는 어휘발달지연을 동반한 $\mathrm{ADHD}$ 아동이 가장 취약함 을 보이고, 오류를 찾고 수정하는 능력이 단순 $\mathrm{ADHD}$ 아동과 비교 해서도 상당히 낮은 것으로 나타나 이러한 어휘지식의 중요성을 다 시 한번 확인할 수 있었다. 이는 어휘발달지연을 동반한 $\mathrm{ADHD}$ 아 동은 위에서 언급한 충동성이나 주의력의 결함, 그리고 실행기능의 문제와 함께 부족한 어휘지식으로 인해 이해모니터링 과제에서의 수행력이 가장 저조했을 것으로 해석할 수 있을 것이다.

둘째, 오류유형 간에 오류를 찾고 수정하는 데 차이가 있는지를 살펴보았다. 연구결과 세 집단 모두 내적비일관성 오류를 찾고 수 정하는 데 가장 어려움을 보였으며, 외적, 어휘비일관성 오류 순으 로 수행력이 좋은 것으로 나타났다. 이러한 패턴은 세 집단 모두에 서 비슷하게 나타났다. 통계적으로도 단순 $\mathrm{ADHD}$ 아동과 일반 아 동은 내적비일관성 오류와 다른 두 오류유형 간에 유의한 차이가 있는 것으로 나타났고, 어휘발달지연을 동반한 $\mathrm{ADHD}$ 아동들은 내적비일관성 오류와 외적비일관성 오류를 찾고 수정하는 데 모두 어려움을 보이면서 두 오류 간에는 통계적 차이를 보이지 않았다. 글에 포함된 오류를 찾고 수정하는 과제를 통해 이해모니터링을 살 펴본 연구들은 내적비일관성 오류가 가장 어려운 오류유형임을 일 관적으로 보고하였다(Baker, 1984; Park \& Yoon, 2020). 내적비일
관성 오류는 이미 들어온 정보를 유지하면서 새로운 정보를 처리해 야 하는 작업기억 능력이 필요하다. 즉, 앞서 읽은 내용을 기억하면 서 이어지는 내용을 함께 통합해야 부적절한 어휘나 모순되는 내 용을 찾을 수 있는데, $\mathrm{ADHD}$ 아동의 작업기억 결함이 글의 내용 을 비교하고 분석하면서 오류를 확인하는 것을 어렵게 하였다. 또 한 어휘발달지연을 동반한 $\mathrm{ADHD}$ 아동은 단순 $\mathrm{ADHD}$ 아동이나 일반 아동과 다른 특성을 보이기도 하였는데, 이들은 글의 전체적 인 통합을 통해 오류를 확인하기 보다는 각 문장이나 문장 내 어휘 나 철자 등의 지엽적인 측면에 초점을 두는 모습을 보였다. 예를 들 면, 어떤 내용이 이상하다고 보기보다는 '매연의 글자들이 이상해 요’ 등의 모습들이 빈번하게 관찰되었다. 이러한 특성은 어휘발달 지연을 동반한 $\mathrm{ADHD}$ 아동들의 어휘지식 부족과 정보를 통합하 는 작업기억 능력의 결함이 더해져 내용의 전반적 측면보다 개별적 인 부분에 초점을 맞추면서 전체적인 내용을 통합해서 오류를 찾 고 수정하는 내적비일관성 오류에서 더 저조한 결과를 보인 이유로 설명할 수 있을 것이다. 텍스트를 잘 이해하기 위해서는 글의 주제 를 파악하고, 중심내용을 연결하고, 중요하지 않거나 지엽적인 정 보는 억제하면서 응집력 있게 글을 재조직화해야 하는데, $\mathrm{ADHD}$ 아동의 제한된 주의력, 작업기억 능력과 억제 능력은 이를 어렵게 하고 결국 이해모니터링의 수행력에 영향을 미쳤다고 볼수 있다.

그 다음으로 외적비일관성 오류를 찾고 수정하는 데 어려움을 보이는 것으로 나타났다. 외적비일관성 오류는 독자가 가진 사전지 식과 어긋난 오류이다. 본 연구에서는 각 어휘의 의미적 속성과 반 대되는 어휘를 포함하였으며, 본 연구의 대상자인 초등 3-5학년의 아동이 충분히 알 수 있는 의미적 속성이 뚜렷한 어휘들을 사용하 여 오류를 구성하였기 때문에 비교적 단순한 언어 및 인지처리과정 을 거쳐 오류를 찾고 수정할 것으로 예측하였다. 하지만 어휘발달 지연을 동반한 $\mathrm{ADHD}$ 아동뿐 아니라 단순 $\mathrm{ADHD}$ 아동도 일반 아 동과 비교 시 상대적으로 수행력이 낮은 것으로 나타났다. 이는 외 적비일관성 오류를 사용하여 $\mathrm{ADHD}$ 아동의 이해모니터링을 살펴 본 Nam 등(2012)의 연구와도 일치하는 결과로, 읽기이해에 어려움 이 없는 $\mathrm{ADHD}$ 아동도 외적비일관성 오류를 찾고 수정하는 데 어 려움을 보이는 것으로 나타났다. 본 연구에서 외적 비일관성 오류 는 한 문장 내에서 사전지식에 반하는 모순되는 정보가 있는 것으 로 예를 들면 문장의 첫 부분이 '설날은'-으로 시작하고 '계절은 여 름에 해당한다'로 끝나 여름이 오류라는 것을 찾아야 한다. $\mathrm{ADHD}$ 아동의 부주의함이 문장 내에서 단어나 핵심내용을 기억하는 방 해하면서 같은 문장 내에서의 모순되는 정보를 찾는 데에도 영향 을 미친 것으로 보인다. 또한 작업기억 또한 영향을 미치는데, 한 문 장일지라도 앞에 나온 정보(설날)를 기억하고 새롭게 나오는 정보 
인 계절(여름)을 확인하며 이 문장의 내용을 통합하고 부적절하게 사용된 어휘를 파악해야 함에도 불구하고 작업기억의 제한이 이 러한 정보의 통합을 방해하고 부적절함을 인식하는 데 어려움을 야기했을 것이다.

본 연구에서는 외적비일관성 오류가 내적비일관성 오류 다음으 로 수행력이 낮은 오류로 나타났는데, 이는 언어발달장애의 읽기이 해모니터링 능력을 살펴본 선행연구(Park \& Yoon, 2010)와는 다른 결과이다. 상이한 결과가 나타난 이유는 본 연구가 설명담화이며, 어휘발달지연과 $\mathrm{ADHD}$ 를 동반한 아동이 포함되어 있기 때문으로 설명할 수 있다. 선행연구에서는 이야기담화를 사용하여 이해모니 터링을 했기 때문에 이야기는 설명담화에 비해 비교적 친숙하고 일 상적인 어휘를 사용하기 때문에 사전지식에 반하는 외적비일관성 오류를 찾는 것이 쉬웠다면, 설명담화 읽기이해모니터링을 살펴본 본 연구에서는 계절이나 가뭄 등과 같은 사전지식을 필요로 하는 어휘들이 포함되어 세 집단 모두에서 내적비일관성 오류 다음으로 어려운 오류유형으로 나타났다고 설명할 수 있다. 또한 단순 $\mathrm{ADHD}$ 아동과 일반 아동 집단에서는 내적비일관성 오류는 다른 두 오류 유형과 통계적 차이가 있었으며, 외적비일관성 오류와 어휘비일관 성 오류 간에는 통계적으로 유의한 차이가 나타나지 않았다. 반면, 어휘발달지연을 동반한 $\mathrm{ADHD}$ 아동은 내적비일관성 오류와 외적 비일관성 오류에서만 차이가 없는 것으로 나타나 내적비일관성 오 류만큼 외적 비일관성 오류에서도 어려움을 보인 것으로 나타났다. 이러한 결과는 $\mathrm{ADHD}$ 아동의 부주의함이나 작업기억 제한뿐 아 니라 이들의 어휘지식의 제한도 함께 영향을 미친 것으로 해석할 수 있다.

특히, 마지막으로 세 집단 모두 어휘비일관성 오류를 가장 잘 찾 고, 수정하는 것으로 나타났는데, 이는 무의미 단어가 자신의 어휘 집 내 있는지 여부만 구별하는 되는 단순 처리 과정이기 때문으로 설명할 수 있을 것이다. 다른 오류유형에 비해 비교적 쉽게 오류를 찾고 수정할 수 있음에도 불구하고 어휘 능력에 차이가 없는 단순 $\mathrm{ADHD}$ 아동도 일반 아동에 비해 낮은수행력을 보인 이유는 $\mathrm{ADHD}$ 아동의 취약한 추론 능력에 기인한 것으로 설명할 수 있다(Berthiaume et al., 2005, 2010; McInnes, Humphries, Hogg-Johnson, \& Tannock, 2003). 추론 능력은 읽기이해에 필요한 능력이며, 문자적 으로 주어진 정보뿐 아니라 앞뒤 문맥정보와 독자의 배경지식을 통 합하여 내포된 의미도 파악할 수 있도록 한다(Van den Broek et al., 2005). 읽기이해는 텍스트에서 주어진 정보와 독자의 지식이 상호 작용하고, 추론과정이 더해져 가능해진다. 어휘비일관성 오류를 확인 및 수정하기 위해서는 어휘지식 뿐 아니라 앞뒤 문맥을 통한 추론과정을 통해 무의미단어를 대체할 적절한 어휘를 찾아야 한
다. 예를 들어, 본 연구 과제에 포함된 어휘비일관성 오류인 '설날의 대표적인 음식으로는 벙피가 있다'의 '벙피’라는 무의미단어를 수 정할 때 글의 흐름상 설날에 먹는 음식으로 '떡국'이라는 것을 추론 할 수 있다. 앞에 언급된 내용을 기억하여 반영하는 추론이 가능하 지 않다면 적절한 어휘를 확인하여 수정하는데 어려움을 나타낼 것이다. 또한 어휘발달지연을 동반한 $\mathrm{ADHD}$ 아동은 추론 능력의 결함 뿐 아니라 이들의 저조한 어휘지식이 담화 속 어휘비일관성 오 류를 확인 및 수정의 영향을 준 것으로 보인다.

읽고 이해하는 것은 읽은 것에 대해 심적 표상(mental representation)을 구축하는 것이다. 심적 표상을 구축하기 위해서는 우선 어휘나 문법과 같은 언어지식 뿐 아니라 작업기억이나 주의집중과 같은 상위인지 능력도 동반이 되어야 한다. 이러한 토대 위에서 더 높은 수준의 추론과 이해모니터링 능력을 통해 텍스트의 내용을 점검하고 마지막으로 독자의 배경지식을 통합하여 읽은 것을 이해 하게 된다(Rawson \& Kintsch, 2005). 읽기이해에서 핵심적인 역할 을 하는 어휘 능력이 지연되어 있거나 주의집중, 작업기억, 억제 등 읽기이해와 관련된 상위인지 전략에서 취약함을 보이는 $\mathrm{ADHD}$ 아동의 특성이 이들의 읽기이해모니터링을 방해하고, 최종적으로 성공적인 읽기이해를 어렵게 한다고 해석할 수 있을 것이다.

본 연구의 결과를 통해 $\mathrm{ADHD}$ 아동은 언어발달지연 동반의 여 부와 관계없이 읽기이해모니터링에서 어려움을 보인다는 것을 확 인할 수 있었다. 본 연구에서는 읽기이해 검사를 실시하지 않았기 때문에 이들의 읽기이해모니터링 능력이 얼마나 읽기이해와 관련 이 있는지를 직접적으로 확인하지는 못했지만 이미 많은 선행연구 를 통해 나타난 읽기이해모니터링과 읽기이해 간의 관련성이나 설 명력을 고려한다면 이들의 저조한 이해모니터링 능력이 읽기이해 에 부정적인 영향을 미칠 것으로 예측할 수 있을 것이다. 이는 읽기 이해에서 어려움을 보일 때 이해모니터링 능력도 함께 평가해야 하 며, 중재에서 고려되어야 한다는 것을 보여준다.

본 연구에서는 읽기이해모니터링에 영향을 미치는 원인을 실행기 능의 취약함 등으로 설명했지만 본 연구에서 직접적인 평가는 이루 어지지 못하였다. 후속 연구에서는 다양한 실행기능을 포함한 다양 한 상위인지처리요인을 포함하여 이해모니터링 능력을 살펴보고, 읽기이해와의 관련성을 구체적으로 살펴보는 것이 필요할 것이다.

\section{REFERENCES}

Baker, L. (1984). Children's effective use of multiple standards for evaluating their comprehension. Journal of Educational Psychology, 76(4), 588.

Baker, L., \& Anderson, R. L. (1982). Effect of inconsistent information on text 
processing: evidence for comprehension monitoring. Reading Research Quarterly, 17(2), 281-294.

Barkely, R. A. (1997). Attention deficit/hyperactivity disorder, self-regulation, and time: toward a more comprehensive theory. Journal of Developmental and Behavioral Pediatrics, 18(4), 271-279.

Berthiaume, K. S., \& Lorch, E. P., \& Milich, R. (2005). Cognitive engagement and story comprehension in typically developing children and children with ADHD from preschool through elementary school. Developmental Psychology, 42(6), 1206-1219.

Berthiaume, K. S., \& Lorch, E. P., \& Milich, R. (2010). Getting clued in: Inferential processing and comprehension monitoring in boys with ADHD. Journal of Attention Disorders, 14(1), 31-42.

Bialystok, E. (2001). Bilingualism in development: language, literacy, and cognition. New York, NY: Cambridge University Press.

Brock, S. E., \& Knapp, P. K. (1996). Reading comprehension abilities of children with attention-deficit/hyperactivity disorder. Journal of Attention Disorders, 12(6), 1-8.

Choi, Y. K., \& Jung, H. Y. (2014). A comparative study on reading fluency and reading comprehension between $\mathrm{ADHD}$ children and non-ADHD children. Journal of Emotional \& Behavioral Disorders, 30(4), 133-152.

Garner, R., \& Reis, R. (1981). Monitoring and resolving comprehension obstacles: an investigation of spontaneous text lookbacks among upper-grade good and poor comprehenders. Reading Research Quarterly, 16(4), 569582.

Gombert, J. E., \& Gombert, J. É. (1992). Metalinguistic development. University of Chicago Press.

Kim, K. (2014). The Relation between reading comprehension monitoring and reading comprehension of low achieving students. The Journal of Learner-Centered Curriculum and Instruction, 14(11), 221-238.

Kim, K. H. (2003). Vocabulary for Korean language education by grade. Seoul: Bagijeong.

Kim, Y. S. (2017). Systematic and precise instruction of reading and writing. Seoul: Hakjisa.

Kim, Y. S., So, Y. K., Noh, J. S., Choi, N. K., Kim, S. J., \& Koh, Y. J. (2003). Normative data on the Korean ADHD rating scales (K-ARS) for parents and teacher. Journal Korean Neuropsychaiatric Association, 42(3), 352-359.

Kim, Y. T., Hong, G. H., Kim, K. H., Jang, H. S., \& Lee, J. Y. (2009). Content and reliability analyses of the receptive and expressive vocabulary test (REVT). Seoul: Seoul Community Rehabilitation Center.

McInnes, A., Humphries, T., Hogg-Johnson, S., \& Tannock, R. (2003). Lis- tening comprehension and working memory are impaired in attentiondeficit hyperactivity disorder irrespective of language impairment. Journal of Abnormal Child Psychology, 31(4), 427-443.

Ministry of Gender Equality and Family. (2010). Let's read and talk together. Seoul: Korea Institute for Health and Social Affairs

Miller, A. C., Keenan, J. M., Betjemann, R. S., Willcutt, E. G., Pennington, B. F., \& Olson, R. K. (2013). Reading comprehension in children with ADHD: cognitive underpinnings of the centrality deficit. Journal of Abnormal Child Psychology, 41(3), 473-483.

Nam, Y. J., Hwang, M., \& Lim, J. (2012). Comprehension monitoring abilities in children with attention deficit hyperactive disorder. Korean Journal of Learning Disability, 9(2), 215-229.

Noh, S., \& Shin, H. (2007). The effect on story-mapping training for reading comprehension and reading attitude of children with ADHD. Journal of Special Education, 18, 1-22.

Oakhill, J., Hartt, J., \& Samols, D. (2005). Levels of comprehension monitoring and working memory in good and poor comprehenders. Reading and Writing, 18(7), 657-686.

Oh, J. E. (2005). Story recall of Korean school-age children with ADHD (Master's thesis). Hallym University, Chuncheon, Korea.

Oh, K., Kim, Y., Ha, E., Lee, H., \& Hong, K. (2010). Child behavior checklist for ages 6-18. Seoul: HUNO.

Ouellette, G. P. (2006). What's meaning got to do with it: the role of vocabulary in word reading and reading comprehension. Journal of Educational Psychology, 98(3), 554-566.

Pae, S., Jung, K. H., Kim, M. B., \& Jin, Y. S. (2010). Read and speak together. Seoul: Ministry of Gender Equality and Family. Unpublished manuscript.

Pae, S., Kim, M., Yoon, H., \& Jang, S. (2015). Korean Language-based Reading Assessment (KOLRA). Seoul: Hakjisa.

Park, S. M., \& Shin, M. S. (2010). Comparison of executive function in children with $\mathrm{ADHD}$ and anxiety disorder. Journal of the Korean Academy of Child and Adolescent Psychiatry, 21(3), 147-152.

Park, M., \& Yoon, H. (2020). Reading comprehension monitoring in schoolaged children with language impairment. Communication Sciences \& Disorders, 25(4), 797-808.

Park, H. W. (2014). Korean version of comprehensive test of nonverbal intelligence-second edition (K-CTONI-2). Seoul: Mindpress.

Pearson, C. R., Simoni, J. M., Hoff, P., Kurth, A. E., \& Martin, D. P. (2007). Assessing antiretroviral adherence via electronic drug monitoring and self-report: an examination of key methodological issues. AIDS and Be- 
havior, 11(2), 161-173.

Pennington, B. F., \& Ozonoff, S. (1996). Executive functions and developmental psychopathology. Journal of Child Psychology and Psychiatry, 37(1), 51-87.

Perfetti, C., \& Adlof, S. M. (2012). Reading comprehension: a conceptual framework from word meaning to text meaning. In J. P. Sabatini, E. R. Albro, \& T. O’Reilly (Eds.), Measuring up: advances in how we assess reading ability (pp. 3-20). Lanham, MD: Rowman \& Littlefield Education.

Purvis, K. L., \& Tannock, R. (1997). Language abilities in children with attention deficit hyperactivity disorder, reading disability, and normal controls. Journal Abnormal Child Psychology, 25(2), 133-144.

Rawson, K. A., \& Kintsch, W. (2005). Rereading effects depend on time of test. Journal of Educational Psychology, 97(1), 70-80.

Ricketts, J., Nation, K., \& Bishop, D. V. (2007). Vocabulary is important for some, but not all reading skills. Scientific Studies of Reading, 11(3), 235-257.

Sandra, F. (2012). How to reach and teach children with ADD/ADHD: practical techniques, strategies, and interventions (Vol. 3). John Wiley \& Sons.
Stern, P., \& Shalev, L. (2013). The role of sustained attention and display medium in reading comprehension among adolescents with $\mathrm{ADHD}$ and without it. Research in Developmental Disabilities, 34(1), 431-439.

Tannock, R., \& Schachar, R. (1996). Executive dysfunction as an underlying mechanism of behavior and language problems in attention deficit hyperactivity disorder. In J. H. Beitchman, N. J. Cohen, M. M. Konstantareas, \& R. Tannock (Eds.), Language, learning, and behavior disorders: developmental, biological, and clinical perspectives (pp. 128-155). Cambridge University Press.

Van den Broek, P., Kendeou, P., Kremer, K., Lynch, J. S., Butler, J., White, M. J., et al. (2005). Assessment of comprehension abilities in young children. In S. Paris \& S. Stahl (Eds.), New directions in assessment of reading comprehension (PP. 107-130). Mahwah, NJ: Lawrence Erlbaum.

Walczyk, J. J., \& Hall, V. C. (1989). Effects of examples and embedded questions on the accuracy of comprehension self-assessments. Journal of Educational Psychology, 81(3), 435. 
Appendix 1. Example of a expository discourse and error types

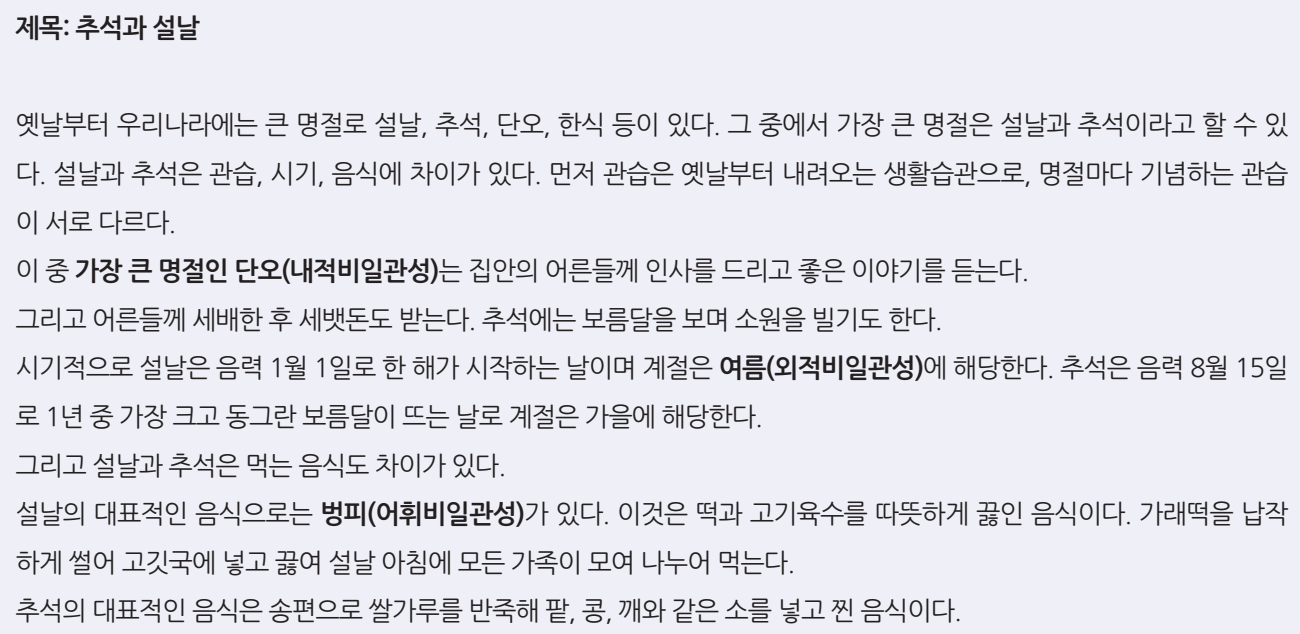




\section{국문초록}

\section{초등 3-5학년 어휘발달지연을 동반한 ADHD 아동과 단순 ADHD 아동의 설명담화 읽기이해모니터링 능력 박경민 · 윤효진 \\ 조선대학교 언어치료학과}

배경 및 목적: 본 연구는 초등 3-5학년 어휘발달지연을 동반한 $\mathrm{ADHD}$ 아동, 일반적인 어휘발달을 하는 단순 $\mathrm{ADHD}$ 아동, 그리고 학 년을 일치시킨 일반 아동의 설명담화 읽기이해모니터링 능력을 살펴보고자 하였다. 방법: 연구 대상자는 초등 3-5학년의 어휘발달지연 을 동반한 $\mathrm{ADHD}$ 아동 19 명, 일반적인 어휘발달을 하는 단순 $\mathrm{ADHD}$ 아동 17 명, 그리고 학년을 일치시킨 일반 아동 20명이다. 아동에 게 비교대조와 원인결과 유형의 두 설명담화를 읽은 후에 글에 포함된 어휘, 외적, 내적 비일관성 오류를 찾고 수정하도록 요구하였다. 결과: 어휘발달지연을 동반한 $\mathrm{ADHD}$ 아동의 이해모니터링 수행력이 가장 저조하였으며, 단순 $\mathrm{ADHD}$ 아동도 일반 아동보다 통계적으 로 낮은 수행력을 나타냈다. 세 가지 오류유형 중 세 집단 모두 내적비일관성 오류에서 가장 어려움을 보였다. 논의 및 결론: 언어발달에 어려움이 없는 $\mathrm{ADHD}$ 아동도 이해모니터링에서 취약함을 보였으며, 어휘발달지연을 동반한 아동은 이들의 부족한 어휘지식으로 인 해 더욱 더 이해모니터링을 어려움을 보이는 것으로 나타났다. 이는 이들이 가진 실행기능의 결함 등이 읽기이해모니터링에 영향을 미 치고, 이는 읽기이해에 부정적인 영향을 미칠 것으로 해석할 수 있다.

핵심어: 주의력결핍 과잉행동장애(ADHD), 학령기 아동, 읽기이해, 이해모니터링, 어휘발달지연

본 연구는 제 1 저자(박경민)의 석사학위논문을 수정 및 보완하였음.

\section{참고문헌}

김경선 (2014). 읽기 저성취 아동의 읽기이해 점검과 읽기이해와의 관계 분석. 학습자중심교과교육연구, 14(11), 221-238.

김광해 (2003). 등급별 국어교육용 어휘. 서울: 박이정.

김영숙 (2017). 읽기 \& 쓰기 교육. 서울: 학지사.

김영신, 소유경, 노주선, 최낙경, 김세주, 고윤주 (2003). 한국어판 부모 및 교사용 $\mathrm{ADHD}$ 평가 척도 (K-ARS)의 규준연구. 신경정신의학, 42(3), 352359.d

김영태, 홍경훈, 김경희, 장혜성, 이주연 (2009). 수용·표현 어휘력 검사(Receptive \& Expressive Vocabulary Test, REVT). 서울: 서울장애인복지관. 남윤정, 황민아, 임종아 (2012). ADHD 아동의 읽기 이해점검능력. 학습장애연구, 9(2), 215-229.

노승림, 신현기 (2007). 이야기도식을 활용한 읽기훈련이 ADHD 아동의 읽기 이해 및 읽기 태도에 미치는 영향. 특수교육논총, 18, 1-22.

박민영, 윤효진 (2020). 학령기 언어장애 아동의 읽기이해모니터링. Communication Sciences \& Disorders, 25(4), 797-808.

박순말, 신민섭 (2010). 주의력결핍 과잉행동장애, 불안장애 아동의 실행기능 비교. 소아청소년정신의학, 21(3), 147-152.

박혜원 (2014). 한국비언어 지능검사(Korean comprehensive Test of Nonverbal Intelligence-Second Edition, K-CTONI-2). 서울: 학지사.

배소영, 김미배, 윤효진, 장승민 (2015). 한국어 읽기 검사(Korean Language-based Reading Assessment, KOLRA). 서울: 학지사.

배소영, 정경희, 김미배, 진연선 (2010). 함께 읽고 말해요. 서울: 여성가족부(미간행).

오경자, 김영아, 하은혜, 이혜련, 홍강의 (2010). 아동· 청소년 행동평가척도 부모용 CBCL 6-18. 서울: (주) 휴노.

오정은 (2005). 학령기 ADHD아동의 이야기 회상산출 특성. 한림대학교 대학원 석사학위논문.

최영경, 정훈영 (2014). ADHD 아동과 일반아동 간의 읽기 유창성 및 읽기 이해력 비교 연구. 정서 · 행동장애연구, 30(4), 133-152.

\section{ORCID}

박경민(제1저자, 박사과정 https://orcid.org/0000-0002-6059-7529); 윤효진(교신저자, 교수 https://orcid.org/0000-0003-0011-2566) 